\title{
ALGUNOS FUNDAMENTOS PARA EL ANÁLISIS DISCURSIVO Y SEMIÓTICO DE LAS REPRESENTACIONES DE LOS ACTORES DEL CONFLICTO EN LA CARICATURA POLÍTICA EN COLOMBIA*
}

\section{THE INTERACTION BETWEEN VISUAL AND WRITTEN TEXTS: BASIS FOR A METHOD OF DISCOURSE ANALYSIS OF THE REPRESENTATIONS OF THE ACTORS OF THE POLITICAL CONFLICT IN THE COLOMBIAN PRESS}

\author{
Rafael Alberto Barragán Gómez ${ }^{\star *}$
}

\begin{abstract}
Resumen
En el contexto del conflicto político que vive la nación colombiana desde hace más de cincuenta años se puede corroborar la enorme influencia de la prensa escrita, especialmente en las décadas de los años cuarenta y cincuenta, en la consolidación de representaciones de los avatares del conflicto y, en especial, de sus protagonistas. Si bien dicho fenómeno se ha abordado desde diversas disciplinas, no abundan los estudios sobre el rol desempeñado por el lenguaje 0, para ser más precisos, el discurso en tales representaciones. A eso se suma el escaso aprovechamiento de las teorías y métodos útiles para dar cuenta de las formas en que interactúan los variados sistemas semióticos que, en el caso de la gran prensa escrita de la época, constituyen auténticas prácticas discursivas de gran impacto en la sociedad. Dichas prácticas establecieron como agenda social el estado del proceso político al tiempo que actuaron como vehículo privilegiado para la consolidación de representaciones sobre el rival.
\end{abstract}

Este artículo, continuación de un proyecto sobre la imagen como discurso, aborda las complejas interrelaciones entre los textos escritos y los textos visuales, concretamente la caricatura política, un subgénero del dibujo con gran arraigo en la tradición periodística colombiana. Para ello se intentan conciliar nociones provenientes de la semiótica visual y el análisis del discurso (perspectivas críticas y sistémico-funcionales) partiendo de la base de que la coexistencia de este tipo no es meramente casual sino que obedece a un criterio de elaboración de un tipo de discurso multisemiótico, sustentado en la noción de multimodalidad, que garantiza su eficacia.

Se espera elaborar un análisis inicial de este tipo de textos constituidos como espacio ideal donde se reflejan y refractan ideologías políticas en un escenario tan complejo como el del conflicto colombiano.

Palabras clave: Multimodalidad; discurso, conflicto, caricatura.

Artículo recibido: 27/07/2013 Aprobado: 31/08/2013

* Este artículo desarrolla con más detalle las tesis propuestas en la ponencia que lleva el mismo título y que fue presentada en el marco del VIII Congreso de la Asociación de Lingüística Sistémico Funcional que tuvo lugar en Montevideo (Uruguay) entre el 27 y 29 de septiembre de 2012.

** Magister en semiótica. Profesor titular Escuela de Idiomas, Universidad Industrial de Santander. Email: rbarraga@uis.edu.co 


\section{Abstract}

In the context of the political conflict that Colombia has lived for more than fifty years, it is possible to corroborate the enormous influence of the press, especially in the decades of the forties and fifties, on the consolidation of representations on the characteristics of the conflict, and especially of its protagonists. While it is true that this phenomenon has been approached from various disciplines, not often it has been attempted to give an explanation of the role played by language, or to be more precise, the discourse on such representations. In addition, there is an insufficient or unknown theoretical and methodological basis which results unable to account for the ways they interact with the various semiotic systems which, in the case of the great newspapers of the time, constitute discursive practices of truly great impact on society. Such practices not only reflected the state of the political process, but it also served as a vehicle for the consolidation of representations about the opponent, in short, they represented an ideological confrontation scenario.

This work, which is the continuation of another research project on the image as discourse, addresses the complex interrelations between written texts and visual texts, specifically the political cartoon, which is a subgenre of the drawing that is very cultivated and has wide acceptance in Colombia today. To achieve this, it will be attempted to reconcile the notions of visual semiotics and discourse analysis, on the basis that such coexistence is not accidental, but that this is due to a criterion of development of a kind of multisemiotic discourse which necessarily calls for multimodal readings to ensure its effectiveness.

It is expected to develop a model of analysis of the press's multimodal discourse as ideal space where political ideologies are reflected and refracted in a scenario as complex as the Colombian conflict.

Key words: Multimodal speech conflict.

\section{El conflicto armado colombiano y su representación en la caricatura política}

En la convulsa historia del continente americano sobresalen la duración e intensidad de la confrontación armada en Colombia, en parte como resultado de un sistema político cerrado y excluyente que ha conducido, tras una primera fase de «terror concentrado» que suprimió la política, a una lucha fratricida entre clases dominantes y entre estas y los distintos movimientos sociales populares (Sánchez, 2008, pág. 29).

La actual violencia política tiene su origen en las interminables y sucesivas guerras civiles de finales del siglo XIX durante las cuales dos facciones hegemónicas lucharon feroz y encarnizadamente por la imposición de su ideario y por el consecuente empoderamiento en el escenario político derivado de la victoria por las vías de hecho.

Surgido inicialmente como un conflicto partidista, este extendió sus tentáculos hacia otras fuerzas hasta entonces invisibilizadas que buscaban espacios de participación en el limitado espectro político nacional, hasta llegar a los niveles de complejidad y degradación actuales.
Llama poderosamente la atención que sea uno de los más destacados estudiosos de la relación entre la guerra y la política en Colombia quien exprese, en una nota marginal de uno de los libros donde intenta explicar la «politización presocial» que caracterizó desde un principio la presencia de los partidos políticos tradicionales en la vida del país, que «carecemos todavía de un análisis del vocabulario de la violencia (Sánchez, 2008, pág. 30)».

Justamente esta preocupación tiene que ver con que, al intentar explicar esa politización presocial que caracteriza a la actividad partidista en Colombia y se refiere a la manera como los partidos tradicionales «responden ante todo a las solidaridades comunitarias, es decir, que pertenecen propiamente hablando al orden de lo arcaico y prepolítico y que [...] llegaron a las gentes antes que el Estado o el sentido de la nación» (Sánchez, 2008, pág. 30), brillen por su ausencia análisis de cómo dicha «desarticulación de lo social» en la guerra política se expresa en el lenguaje.

Con base en esta certeza, puede afirmarse que está abierto un campo fértil para los estudios sobre las prácticas discursivas mediante las cuales se ha legitimado la 
eliminación física y simbólica del opositor político quien es visto como enemigo, por parte de agrupaciones de las más variadas tendencias ideológicas.

Este trabajo intentará plantear los fundamentos de un análisis de estas prácticas discursivas en el caso específico de la caricatura política, en especial por constituir todo un género dentro del periodismo escrito, por su rica tradición en la prensa colombiana y, fundamentalmente, por su naturaleza multisemiótica (Fairclough, 1995 y 2001) que la convierte en una forma multimodal de representación (Kress, 2005; Kress y van Leeuwen, 2006; Caldeira y Oliveira, 2011) donde los modos de la escritura alfabética y la imagen visual suelen integrarse armónica y no casualmente en un todo perfectamente cohesionado en virtud de la ideología política que defienden. Para ello, intentará conectar las perspectivas críticas del discurso con los abordajes semióticos utilizando como puente los fundamentos de enfoques sistémico funcionales en la línea de M. Halliday.

\section{La prensa escrita y el establecimiento del conflicto como «agenda social»}

El papel de la prensa escrita ha sido fundamental en la representación de la guerra y la política partidistas colombianas. Cada uno de los grandes partidos tradicionales ha dispuesto de sus respectivas tribunas ideológicas:

\section{El periodismo colombiano ha estado desde sus orígenes es- trechamente ligado a intereses ideológicos y partidistas. El curso de la vida política colombiana se entiende mucho mejor cuando está acompañado del análisis del papel de los me- dios impresos en las diversas coyunturas y periodos. Editoriales, noticias, crónicas, columnas de opinión y otros artículos dan cuenta fiel de la intensidad de las contiendas políticas de cada momento (Acevedo, 2009, pág. 57).}

Y no es para menos, pues si se tiene en cuenta que los medios son quienes cumplen prioritariamente con el papel de establecer la agenda social, podemos concluir que la prensa escrita constituye una fuente excepcional para develar el clima político de la nación colombiana, especialmente en el periodo álgido de esta confrontación partidista (décadas del cuarenta y del cincuenta), dado el grado de influencia y el carácter exclusivo que tenían y tienen como medio informativo.

La teoría del establecimiento o fijación de la agenda (agenda setting) proviene de McCombs y Shaw (Sani et al. 2012; Piñuel y Gaitán, 2010) y se aplica específicamente a los medios de comunicación de masas y su potencial para representar o describir asuntos de actualidad con el fin de reorientar y configurar la opinión del público frente a los hechos presentados (Sani et al. 2012, pág. 158). De alguna manera, el predominio de unos temas frente a otros está determinado por la prioridad que los medios les otorgan a ciertos asuntos en una especie de jerarquía que se aprecia en la estructura, los contenidos y, en general, todos aquellos rasgos o modos de significación prototípicos de los géneros periodísticos dentro de los cuales, como ya veremos más adelante, las caricaturas políticas ocupan un lugar importante.

Se puede afirmar que la agenda de los medios se convierte inevitablemente en la agenda pública casi siempre estructurada con arreglo a la manera en que estos la han presentado (Piñuel y Gaitán, 2010, pág. 573).

Es en este sentido como se entiende el papel de la prensa como vehículo y soporte de las representaciones sociales sobre la violencia política en Colombia y por qué, en virtud de su presencia constante y destacada (González, 2009), la caricatura política es un objeto de sumo interés para quien desea establecer el papel del discurso en este periodo traumático que ha dejado cicatrices profundas en generaciones de ciudadanos.

Básicamente, lo que aquí se propone es una forma de abordar los discursos de la prensa escrita como una totalidad donde convergen sistemas de significación diferentes cuyo elemento cohesionador es la ideología política que se refleja en las formas como se representa al opositor, representación que, en todo caso, y siguiendo las tesis de Sánchez (2008), se reduce a la de un enemigo al que hay que eliminar 0 , por lo menos, expulsar de su hábitat.

Pero esta forma de representación no apela a descripciones de individuos en cuanto tales, sino a «un conjunto de rótulos o etiquetas que se constituyen en huellas a través de las cuales se evidencian las formas de ser de los grupos, las maneras de expresarse y los procedimientos o pautas orientadoras de la acción (Pardo, 2007, pág. 18)». Aquí se configura lo que Pardo considera la manera en que «la prensa actualiza lo social en el discurso (Pardo, 2007, pág. 27)».

Esta representación es consistente con la noción de representación socio-cognitiva desarrollada por la psicología social que alude a una serie de conocimientos 
organizados, coherentes y compartidos socialmente sobre objetos, hechos y personajes. Tales saberes se combinan con estructuras afectivas que se corresponden con un sistema axiológico históricamente determinado (Koller, 2012, pág. 20). En el caso de las representaciones mediáticas, se pondrá un especial énfasis en la manera como el dibujo caricaturesco se concentra en ciertos rasgos personales que, de alguna manera, coinciden y exacerban las ideas previas de los consumidores de este tipo de textos. No se debe olvidar que «todo proceso discursivo (...) supone de parte del emisor una anticipación de las representaciones del receptor, imagen anticipada en la cual basa sus estrategias discursivas» (Álvarez, Álvarez y Facuse, 2002, pág. 149).

El establecimiento de la agenda y la forma de representación determina la selección de temas y las formas escogidas para su presentación al tiempo que definen la credibilidad de un contenido específico, incluso si este es presentado en una caricatura política cuyo rasgo definitorio es el de la alteración hiperbólica de la realidad representada. Estas prácticas comunicativas de los medios estarían así generando una «segunda realidad» (Piñuel y Gaitán, 2010, pág. 573) capaz de suplantar incluso a los hechos mismos, que es la manera en que opera la «naturalización» de lo social propia de la ideología y de los dispositivos discursivos puestos a su servicio.

Este concepto de ideología como un saber erróneo, si bien se encuentra en una línea de pensamiento genuinamente marxista (Villoro, 2007), tiene el valor de rescatar los mecanismos mediante los cuales ciertas formas expresivas portan contenidos que van más allá e incluso se superponen a lo reall ${ }^{1}$. Justamente este sería una razón para explicar el permanente recurso a la exageración de rasgos que es inherente a la caricatura política.

Adicionalmente, algunos estudios discursivos abordan la conexión entre lenguaje, imagen y valores construidos en la prensa y que, en el caso que nos ocupa viene a ser determinante, pues es un enfoque que permite entender los valores que determinan el que un hecho sea noticioso 0 no, por ello se habla de valores tales como negatividad, prominencia, consonancia, impacto, novedad, superlati- vidad y personalización como lo que determinan la selección de temas dentro del establecimiento de la agenda mediática (Bednarek y Caple, 2012). Aunque no es el tema de este trabajo, sí puede considerarse viable la inclusión de tales valores dentro de los instrumentos de análisis, en caso de que se pretenda abordar el nivel de las prácticas discursivas.

\section{El potencial comunicativo de la caricatura política en su condición de forma multimodal de significación}

González (2009) considera que la caricatura tiene su origen desde mucho antes de adquirir este nombre, pues ya era un producto habitual de pintores famosos. Da Vinci, Durero, Cranach, entre otros, produjeron caricaturas donde escarnecían al papado y a Lutero:

\begin{abstract}
La palabra caricatura se imprimió por primera vez después de la muerte de su inventor, Annibale Carracci (1560-1609), en la edición de una colección de sus grabados, realizada por Mosini en 1646. (...)En la búsqueda del placer, Carracci describió tres instancias, hasta llegar a lo que llamó caricatura: la naturaleza; la copia literal de la naturaleza; y la alteración de su forma por medio de la acumulación de defectos, sin quitar nada de su parecido. Annibale Carracci habló de la tercera instancia «como causa del placer, es decir, la caricatura».
\end{abstract}

La palabra caricatura proviene del italiano caricare, cargar. Por ello, a este tipo de dibujos se los llamó pequeños retratos cargados. Se dice que los Carracci, cansados de trabajar todo el día en las imágenes perfectas que exigía la Contrarreforma, salían a las arcadas de Bolonia a dibujar de manera burlesca a los transeúntes (González, 2009, pág. 1).

Específicamente, la caricatura política es un mensaje mediático, una ilustración o género del dibujo, elaborado generalmente en un solo recuadro y publicado en la sección editorial o de opinión de periódicos y revistas (Sani et al. 2012, pág. 157). Debe recalcarse que la caricatura política editorial no debe definirse como un texto de natu-

1. Si bien, ideología es un concepto que se aborda en este artículo, se hará de manera tangencial, pues no es propiamente el objeto del presente trabajo; sin embargo, se recomienda revisar dicho concepto en Villoro (2006) para quien la ideología es, ante todo, una creencia errónea que se define desde dos perspectivas, cognoscitiva y social; es decir, e una creencia que no está ni científica ni lógicamente sustentada y cumple una función social de dominación. Marx aplica su concepción de ideología en la crítica al idealismo y a la economía política. Para una revisión de la evolución del concepto de ideología más cercana a la perspectiva discursiva ver Gee (2005). Otra es la perspectiva de van Dijk (1999) quien considera la ideología como un sistema de creencias estructurado desde la cognición social. 
raleza visual que habla por sí solo, pues se estaría pasando por alto el hecho de que su ocurrencia se solo es posible dentro de una totalidad por fuera de la cual no tendría mayor significación ni eficacia.

Por ello es perfectamente lícito que algunos análisis insistan en la importancia del marco donde se inserta la caricatura, pues provee información que orienta su interpretación en una dirección. Aunque no es el objetivo de este trabajo, sí se harán algunas observaciones al respecto debido a que la filiación política del diario que publica la caricatura es coherente con su contenido y este asunto corresponde a las condiciones de producción de estas imágenes².

Un análisis más exhaustivo que el propuesto acá no puede ignorar aquellos significantes que rodean a los textos sometidos a estudio, sean estos visuales o escritos, pues perdería la posibilidad de dar una explicación más acertada de los fenómenos de la representación social mediante prácticas discursivas concretas.

Hecha esta aclaración, este documento propone que una aproximación a la manera como se produce el significado en la caricatura política por lo que, antes de postular los criterios seleccionados para su análisis, enfatiza en su condición multisemiótica (Fairclough, 1995) y multimodal (Kress).

La propuesta de N. Fairclough asume que «texts do not need to be linguistic at all; any cultural artefact (...) can be seen as a text (1995, pág. 4); con lo cual los análisis discursivos pueden y deben ampliar sus fronteras más allá de lo verbal, tanto más si se trata de textos producidos en la sociedad mediática actual.

Fairclough define el texto multisemiótico como aquel «cuya forma semiótica primaria es el lenguaje y que, cada vez más combina el lenguaje con otras formas semióticas (1995, pág. 4). Si bien la preocupación de Fairclough está plenamente justificada, pues para nadie es un secreto la forma como se producen mensajes en la sociedad actual, dicha definición no es tan precisa por cuanto hay productos como la caricatura editorial en los cuales tanto la imagen visual como la escritura (los dos «modos» de comunicación de los que habla Kress [2005]) conforman una totalidad cohesionada complejamente. Como veremos en la sección de análisis, tanto imagen como texto escrito son indispensables para lograr el efecto de sentido propuesto por los creadores.

De mayor trascendencia es la afirmación de Fairclough sobre la tarea del analista o del semiólogo, quienes están obligados a entender que «el análisis textual debe significar un análisis de la textura de los textos, su forma y su organización, y no simples comentarios sobre el contenido de los textos que ignoren la textura (1995, pág. 4)». Tales análisis de la textura convierten a los textos en «indicadores extraordinariamente sensibles de los procesos, relaciones y cambios socioculturales».

Desde este punto de vista es perfectamente válido postular que la caricatura política es una entidad multisemiótica producida como resultado de prácticas discursivas concretas enmarcadas, a su vez, en prácticas sociales históricamente situadas. En efecto, pese al alto grado de correspondencia entre el dibujo caricaturesco y los personajes o conceptos representados casi siempre alegóricamente por aquel, los principales cultores del humor gráfico político en Colombia se han apoyado reiterativamente en un manejo bastante sofisticado del lenguaje escrito, como se verá en la sección de análisis de las muestras seleccionadas en el presente documento.

El concepto de «modo de representación» aparece como correlato del de multisemioticidad viene. Desde la semiótica social (Kress ,2005), se desarrollan unos principios que especifican y relacionan los modos tradicionales de producción de significados (escritura e imagen) con los medios que les dan soporte (libro y pantalla, respectivamente). Estos modos semióticos tienden a hacerse multimodales, básicamente, por el desarrollo

2. En el Análisis Crítico del Discurso (ACD) se proponen tres niveles de análisis de textos (Fairclough, 1995; Koller, 2012, pág. 24) en sentido ascendente: un primer nivel o micro-nivel donde se analiza el texto para dar respuesta al cómo se construye el sentido. Es el nivel que apunta al texto como forma; un segundo nivel intermedio o meso-nivel correspondiente a las prácticas discursivas relativas a la producción, distribución, recepción y apropiación de los textos que responde a la pregunta de quién está involucrado en la producción de un texto y qué género textual se configura; un tercer nivel o macro-nivel que reconstruye el contexto social y trata de responder a la pregunta de qué factores sociales impactan en el texto y en la práctica discursiva. Este trabajo se concentrará en el primer nivel pues el objetivo inicial consiste en establecer las formas significantes que hacen de la caricatura una práctica donde se construyen, refuerzan y promueven ciertas representaciones del otro. Se verá cómo el trabajo se apoya en la idea de establecer correspondencias entre tales niveles de análisis del ACD, las propuestas de análisis visual de la semiótica social y las funciones ideacional, interpersonal y textual de la Lingüística Sistémico Funcional de M. Halliday (Kress y van Leeuwen, 2006, págs. 41-44). 
constante de tecnologías (un proceso de comienza con la invención de la imprenta y no es exclusivo de la época actual, pues la escritura misma es concebida como una tecnología (Ong, 2000). En consecuencia, según Kress, se reestructuran también las maneras de leer los géneros de cada modo (narrativos, para la lectura y expositivos, para los modos visuales).

En este punto la teoría semiótica social se entrelaza con una teoría funcional sobre el lenguaje (como se precisa en la nota pie de página 4), pues al igual que las estructuras lingüísticas las visuales se orientan hacia unas maneras particulares interpretar la experiencia y de establecer interacciones sociales pues, como lo establece Halliday para cualquier semiótica social, lenguaje verbal incluido, los significados pertenecen a la cultura antes que a un modo semiótico particular y ellos son solo medios o recursos para la significación. Esto justifica plenamente la introducción de la noción de gramática visual en tanto los significados producidos por estos modos no son transparentes o naturalmente legibles, sino cultural y convencionalmente establecidos.

Sin embargo, la caricatura editorial, con su marcada orientación política, ya presenta de tiempo atrás estas combinaciones (una «lógica ambigua» [Kress, 2005, pág. 67]) las cuales tienden a desestabilizar nuestras ideas más arraigadas sobre la lectura.

La pregunta, sin embargo, es si dicha particularidad multimodal en las caricaturas no hace parte de la esencia de un tipo de texto que, además de cumplir las funciones comunicativas tradicionalmente atribuidas a la imagen tales como exponer o captar la atención del lector, también pretende expresar una serie de razonamientos lógicamente estructurados, a la manera de las proposiciones que se creían formas exclusivas del lenguaje escrito, pues la combinación de los dos modos referidos constituye la marca de identidad de la caricatura editorial. Esta inquietud es válida si se atiende al concepto de representación social referido anteriormente y en el caso de la caricatura política siempre cabe la pregunta de qué dimensión orienta inicialmente la lectura de un lector promedio.

Puede apreciarse que los modos de la escritura y de la imagen se funden obligando al lector a interpretar elementos que se despliegan en la dimensión temporal (las letras del alfabeto) y en la dimensión espacial (las imáge- nes visuales). La pregunta vigente es ¿cómo se «llena con contenido» (Kress, 2005, pág. 53) este texto complejo si los dos modos aludidos se hallan en una relación de complementariedad? Tal es el reto de un análisis multimodal en textos marcadamente multisemióticos como la caricatura.

\section{Elementos para el análisis de la cari- catura política como género mediático que contribuye a la representación de actores políticos}

Hechas las precisiones teóricas correspondientes, se intentará a continuación formular algunas categorías para el análisis de caricaturas entendidas como textos multisemióticos, de obligada lectura multimodal y cuya función primordial es la de contribuir a la representación social, casi siempre política, de una determinada situación, hecho o personaje.

Tomaremos como base algunos principios de la Semiótica Social de Kress y van Leeuwen (2006) quienes por primera vez extrapolan los principios de la lingüística sistémico funcional de Halliday, concretamente de las tres dimensiones metafuncionales, al estudio de las formas de significación no verbales y, más concretamente, a las de los textos visuales (Kaltenbacher, 2007, pág. 35).

La idea es sencilla, aunque sumamente revolucionaria. En la teoría de Halliday, el estudio del lenguaje es visto por primera vez, no como una descripción de elementos formales que determinan el significado, sino como recursos puestos al servicio de la significación. La gramática, vista así, se torna en un nivel puesto al servicio de la construcción de lo real, de la interacción con otros y de la elaboración misma de multiplicidad de textos. Pero estos significados no surgen aisladamente sino como resultado de la relación estrecha entre tres dimensiones de los sistemas semióticos (modo, campo y tenor) que dan origen a sendas metafunciones: ideacional, interpersonal y textual (Halliday, 1985).

El modo visual de comunicación también cumple estas funciones, solo que lo hace con recursos propios que le son exclusivos y no compiten con el modo verbal. Según Kress y van Leeuwen (2006), la metafunción ideacional hace posible que el modo represente aspectos del mundo tal y como este es experimentado por los humanos. La función interpersonal proyecta las relacio- 
nes entre productores, destinatarios y objetos representados en determinados signos. La función textual indica que todo modo semiótico está en capacidad de formar textos, complejos de signos coherentes entre sí y con el contexto en el que y por el que son producidos.

La gramática visual de los modos semióticos basados en imágenes icónicas dispone de recursos propios: «different compositional arrangements to allow the realization of different textual meanings» (Kress y van Leeuwen, 2006, pág. 43).

El modelo de análisis que se muestra en la siguiente tabla intenta conciliar estas perspectivas, sumando a ello las posibles selecciones de los rasgos definitorios tanto a nivel formal como de contenido (sentidos asociados) que el analista puede llegar a determinar no de forma casual 0 aleatoria sino con base en las convenciones propias de la gramática visual, en general y del modo se significación propia de la caricatura política, en particular. Se establece una descripción básica del tipo de texto; se distribuyen las tres metafunciones en la primera columna y las formas como se expresa en formas significantes 0 medios expresivos en tres niveles: icónico y plástico, establecidos por la retórica de la imagen (Groupe $\mu$., 1993; Joly, 2009; Dondis, 2008) y lingüístico, este último incorporado por el autor, con el fin de satisfacer la exigencia de una lectura multimodal en sentido estricto.
Finalmente, y a manera de ejemplo, más que de análisis exhaustivo, se presentarán algunas caricaturas para aplicarles los aspectos más relevantes de la matriz de análisis propuesta. Se tendrán en cuenta aquellas características comunes a la caricatura política colombiana que, pese a las distancias en el tiempo y las condiciones socio-históricas particulares de cada momento, conforman un estilo propio del humor gráfico nacional debido, en parte, a la persistencia del conflicto político y la dinámica partidista fuertemente centrada en los dirigentes y caudillos más que en las ideas.

Después de mostrar el instrumento de análisis se tomarán como modelo algunos dibujos correspondientes a distintos momentos del acontecer nacional.

En cuanto a las formas de representación narrativa y conceptual, la caricatura apela a al dibujo figurativo de políticos con un alto grado de precisión y técnica en el trazo, de tal manera que no quede duda sobre la identidad de la persona caricaturizada. No obstante, estos personajes suelen ir acompañados de elementos alegóricos que refuerzan la intención comunicativa. En muchos casos, los trazos son fuertes y el dibujo, salvo que ocupen portada, monocromático. Los personajes representados, salvo contadas excepciones, suelen estar desarrollando alguna actividad con lo que se privilegia el sentido del dinamismo de la política colombiana.

Tabla 1. Matriz de análisis semiótico

\begin{tabular}{|c|c|c|c|c|}
\hline \multicolumn{5}{|c|}{$\begin{array}{l}\text { Modo semiótico: Imagen visual/Género: Dibujo/Subgénero: caricatura política/ } \\
\text { Asunto: controversia política bipartidista }\end{array}$} \\
\hline \multirow{2}{*}{$\begin{array}{l}\text { Medio } \\
\text { empleado }\end{array}$} & \multicolumn{4}{|c|}{ Interacción de modos de significación: multimodalidad } \\
\hline & $\begin{array}{l}\text { Nivel icónico } \\
\text { (descripción de } \\
\text { lo perceptible a } \\
\text { primera vista) }\end{array}$ & Nivel plástico & Nivel lingüístico & Sentidos \\
\hline $\begin{array}{l}\text { Ideacional: } \\
\text { Representaciones narrativas } \\
\text { (participantes, eventos, objetos) } \\
\text { Representaciones simbólicas } \\
\text { o conceptuales. Modalidad: modos de } \\
\text { representación de lo real. }\end{array}$ & \multirow{2}{*}{$\begin{array}{l}\text { Imágenes } \\
\text { Colores } \\
\text { Formas }\end{array}$} & $\begin{array}{l}\text { Personajes haciendo algo. } \\
\text { Evento en proceso. } \\
\text { Imágenes estáticas. } \\
\text { Símbolos, alegorías, metáforas. } \\
\text { Grado de realidad de las imágenes } \\
\text { (foto, dibujo, trazo, collage, etc.) }\end{array}$ & $\begin{array}{l}\text { Descripciones escritas. } \\
\text { Títulos y subtitulos. } \\
\text { Numeraciones. }\end{array}$ & $\begin{array}{l}\text { Realismo } \\
\text { Conceptos } \\
\text { Subjetividad } \\
\text { Objetividad }\end{array}$ \\
\hline $\begin{array}{l}\text { Interpersonal: } \\
\text { Relaciones entre participantes } \\
\text { representados y obervador. }\end{array}$ & & $\begin{array}{l}\text { Marco: tamaño, ubicación, distancia. } \\
\text { Perspectiva. } \\
\text { Subjetividad. } \\
\text { Ángulo vertical. }\end{array}$ & $\begin{array}{l}\text { Apelaciones directas al } \\
\text { observador. } \\
\text { Manifestaciones explícitas } \\
\text { del dibujante. } \\
\text { Paráfrasis. } \\
\text { Citas textuales. } \\
\text { Diálogos entre personajes. }\end{array}$ & $\begin{array}{l}\text { Alejamiento } \\
\text { Vínculo } \\
\text { afectivo } \\
\text { Cercanía } \\
\text { Intimidad } \\
\text { Mandato } \\
\text { Advertencia }\end{array}$ \\
\hline $\begin{array}{l}\text { Textual: } \\
\text { Composición } \\
\text { Información dada y nueva } \\
\text { Valor de información }\end{array}$ & & $\begin{array}{l}\text { Ubicación de los elementos. } \\
\text { Conexión entre los elementos. } \\
\text { Resaltado de elementos. } \\
\text { Composición lineal, no lineal, continua, } \\
\text { discontinua, secuencias de imágenes, etc. }\end{array}$ & $\begin{array}{l}\text { Leyendas. } \\
\text { Expresiones en globos } \\
\text { Textos informativos a pie } \\
\text { de cuadro. }\end{array}$ & $\begin{array}{l}\text { Dinamismo } \\
\text { Estatismo } \\
\text { Frenesi } \\
\text { Vértigo }\end{array}$ \\
\hline
\end{tabular}


Véanse, por ejemplo, la imagen 1 donde el presidente Ospina Pérez es presentado como un «chulavita», personaje de escuadrones de la muerte al servicio de la ideología conservadora que en las décadas del 40 y 50 sembraron el terror en la zona andina colombiana. Contrasta con el dinamismo de la imagen 2 donde se muestra al líder liberal Jorge Eliécer Gaitán haciendo uso de armas. Contrastan las representaciones pues, si bien se muestra negativamente a los dos dirigentes, los recursos empleados difieren notablemente. Más figurativo el retrato de Ospina, más esquemático el de Gaitán de quien solo se destacan algunos rasgos sobresalientes de su fisonomía. La perspectiva y el ángulo de la imagen 1 pretenden transmitir una aparente objetividad en la representación con lo que se da un acceso casi que natural al observador reforzado por una composición más ligada al retrato fotográfico que al dibujo. El ángulo de visión está a la altura del observador quien casi que puede mirar directamente a los ojos del personaje. En la imagen 2, por el contrario, el ángulo es oblicuo y se puede apreciar a Gaitán desde arriba. Este hecho carga de subjetividad la mirada del dibujante y minimiza la personalidad del

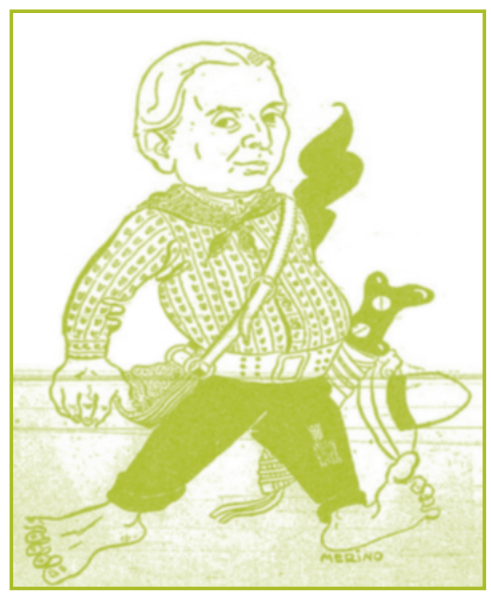

Imagen 1

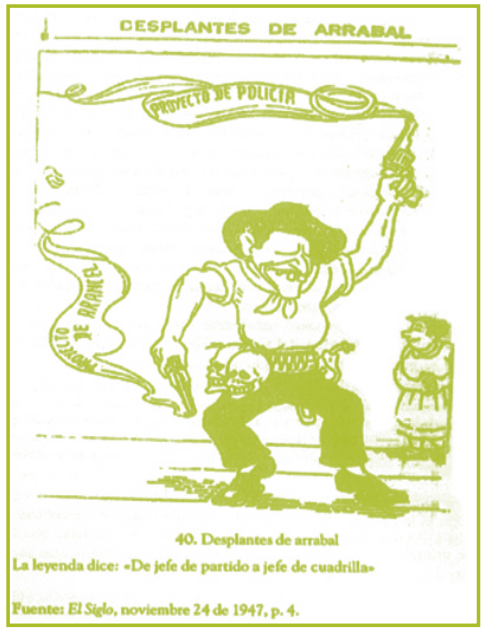

Imagen 2

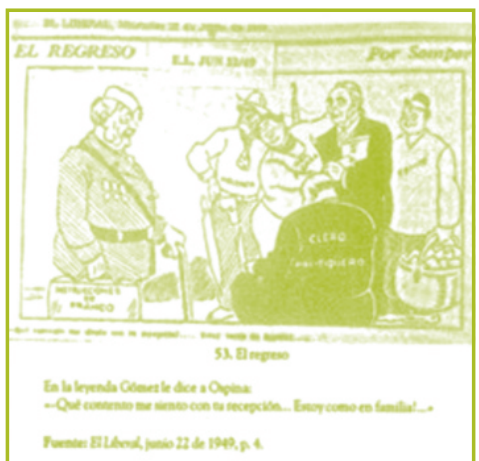

Imagen 3

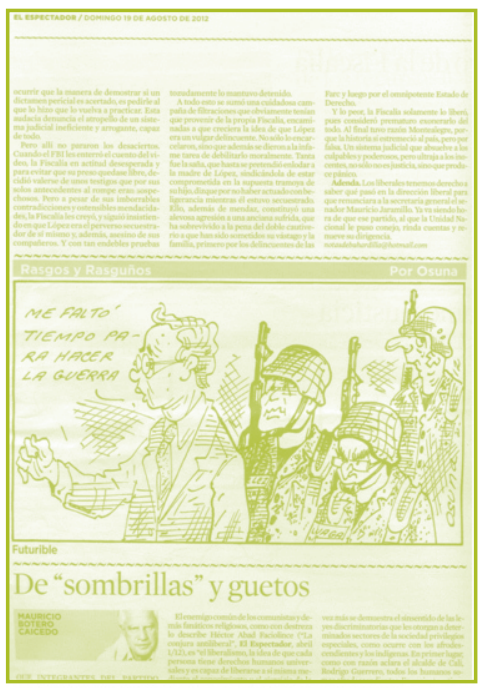

Imagen 4 aguerrido político, reconocido por sus intervenciones emotivas. Hay perspectiva con elementos al fondo y se acude al textos verbales iconizados (las columnas de humo de las armas que esgrime Gaitán). Es interesante apreciar que dos evaluaciones negativas se efectúan por medios distintos probablemente con efectos de sentido inesperados.

Las muestras anteriores sirven para ilustrar que los diarios de la época eran un escenario donde se reflejaba la pugnacidad política entre los partidos conservador y liberal, que históricamente han ejercido la hegemonía política en Colombia, aunque también se reforzaba y mantenían vigentes los estereotipos del opositor que más convenían a la perspectiva ideológica de cada medio.

No obstante, si se comparan nuevamente dos caricaturas (imágenes 3 y 4), una correspondiente al final de la década de los años cuarenta y otra actual, se podrá apreciar la persistencia de la representación figurativa centrada

en los líderes políticos que han determinado el rumbo de la nación colombiana.

Aunque hay diferencias en el ángulo de visión (captados desde un extremo izquierdo en el caso de la imagen 3 y de frente y a la misma altura del observador en la imagen 4) en ambas persiste la intención comunicativa de hacer un registro objetivo de un hecho de actualidad. Los dos ex presidentes ocupan un lugar central en la composición, pese a que no están necesariamente en el centro del cuadro. Son representados con mucha exactitud y en ambos textos hay un uso creativo de recursos retóricos visuales, representaciones metonímicas y personalizaciones en el caso de la imagen 3 (además del ex presidente Laureano Gómez aparecen personajes que encarnan a un todo, tales como el «clero politiquero», la «violencia» y el «fraude» quienes lo esperan a su regreso del exilio en España de donde llega con una maleta que dice «instrucciones de Franco»), en tanto que la imagen 


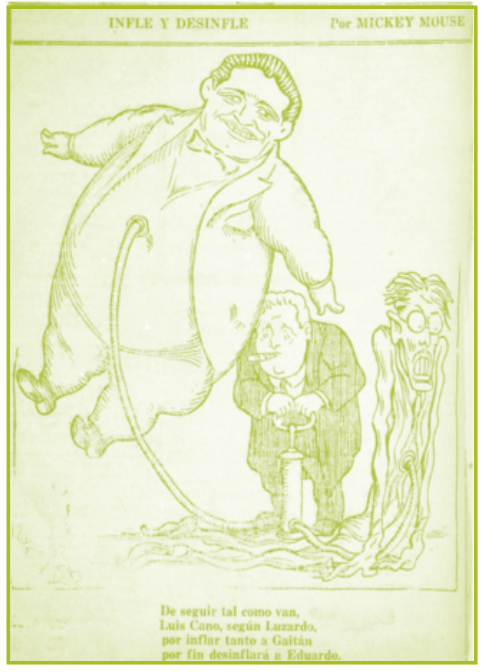

Imagen 5

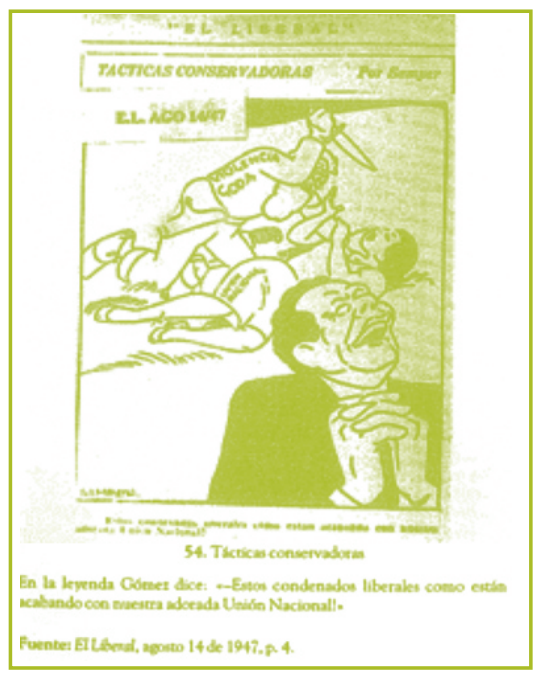

Imagen 6

4 muestra al ex presidente Uribe seguid con un séquito de correligionarios vestidos de militares en una clara alusión a su preferencia por la solución armada al conflicto. Además del equilibrio sobresaliente entre los elementos de la composición y de la perspectiva empleada, el texto escrito juega un papel fundamental en la construcción de sentido.

Sirvan las siguientes imágenes para insistir en que la caricatura política colombiana concentra gran parte de sus intereses en la representación de las figuras públicas como eje central del avatar político del país, incluso si dicha representación hace parte del uso de la ironía con la cual un medio de comunicación cuestiona a otro por sobredimensionar la imagen pública del político liberal Jorge Eliécer Gaitán, como lo hace la imagen 5.

La imagen 6 hace otro tanto, con un manejo notable de la perspectiva, resalta la imagen del político Laureano Gómez con un fondo donde se personalizan «la violencia goda» (nombre con el que se designan en forma un tanto despectiva los militantes del partido conservador) ensañada contra la unión nacional.

\section{Conclusiones}

El análisis de las caricaturas políticas, concebidas como textos indicativos de las estrategias por medio de las cuales se representa discursivamente al opositor político en la prensa colombiana, debería fundamentarse en los siguientes principios:

La caricatura editorial de la época, años cuarentas y cincuentas, no se presenta como un texto estructurado exclusivamente en el modo de la imagen visual; por el contrario, establece con el modo de la escritura una relación complementaria que le confiere su esencia.

Esta forma multimodal conduce necesariamente a la consideración de tales textos como estructuras multisemióticas cuyo análisis debe obedecer, antes que al contenido, a una revisión de la textura o formas en que se cohesionan elementos procedentes de modos distintos de significación. Esto es, a los modos en que se apoya su construcción y a las implicaciones que esto tiene para su interpretación.

La caricatura política surge como resultado de una práctica discursiva concreta, es decir, obedece a unas formas particulares de producción, distribución y consumo del texto (Fairclough, 1995, pág. 135). Esta cuestión puede y debe abordarse en estudios más completos que integren los tres niveles de análisis crítico discursivo referidos en este trabajo.

Es posible plantear, a manera de hipótesis, que La caricatura política en Colombia, si bien ha evolucionado en cuanto al uso de medios para producir efectos de sentido, mantiene la tendencia de concentrar la elaboración del mensaje con el recurso al dibujo figurativo donde la figura de los líderes políticos es central. Esto se refleja en los significantes icónicos, plásticos y verbales que realizan las metafunciones comunicativas esperables en todo modo semiótico.

Finalmente, todas estas prácticas discursivas deben enmarcarse en prácticas sociales específicas que aluden, en líneas generales, a diferentes formas de organización social (cultura, situaciones concretas -en este caso una aguda polarización partidista donde los copartidarios prevalecen sobre los ciudadanos-, etc. (Flaircough, 1995, pág. 134).

\section{Referencias bibliográficas}

Acevedo, D. Política y caudillos colombianos en la caricatura editorial, 1920-1950. Medellín: La Carreta, Editores-Universidad Nacional de Colombia, 2009. 
Álvarez, G., Álvarez, A. y Facuse, M. «La construcción discursiva de los imaginarios sociales: el caso de la medicina popular chilena». Onomázein 7(2002):145-160.

Bednarek, M. y Caple, H. «'Value added': Language, image and news values». Discourse, context \& media 1 (2012):103-113.

Caldeira, L. y Oliveira, S. «Commodified relations (A systemic-functional and multimodal analysisi of the discourse of advertising». Recorte 1: 1-13. Artículo en línea accessible en www.revistas.unicor.br/index.php/recorte/issue/view/40, 2011.

Dondis, D. La sintaxis de la imagen. Introducción al alfabeto visual. Barcelona: Gustavo Gili, 2008.

Fairclough, N. Language and power, $2^{\text {nd }}$. ed., Edimburgo: Pearson, 2001.

Fairclough, N. Critical discourse analysis. Boston: Addison Wesley, 1995.

González, B. La caricatura en Colombia a partir de la independencia. Bogotá: Biblioteca Luis Ángel Arango, 2009.

Gee, J. La ideología en los discursos. Madrid: Morata, 2005.

Groupe $\mu$. Tratado del signo visual. Madrid: Cátedra, 1993.

Halliday, M.A.K. An introduction to functional gramar. London: Edward Arnold, 1985.

Joly, M. Introducción al análisis de la imagen. Buenos Aires: La Marca Editora, 2009.

Kaltenbacher, M. «Perspectivas en el análisis de la multimodalidad: desde los inicios al estado del arte». Revista Latinoamericana de Estudios del Discurso. 7(1)(2007):31-57.

Koller, V. «How to analyse collective identity in discourse: textual and contextual parameters». Critical Approaches to Discourse Analysis Across Disciplines. Artículo en línea accessible en http://cadaad.netjournal. 5(2)(2012):19-38.

Kress, G. El alfabetismo en la era de los nuevos medios de comunicación. Málaga: Aljibe, 2005.

Ong, W. Oralidad y escritura. Tecnologías de la palabra, México, D.F.: Fondo de Cultura Económica, 2000.
Pardo, N. Discurso, impunidad y prensa. Bogotá: Universidad Nacional de Colombia, Facultad de Ciencias Humanas, 2007.

Piñuel, J.L. y Gaitán, J.«Study of the hegemonic discourse about truth and communication in the media's self-referential information, based on the analysis of the Spanish press». Revista Latina de Comunicación Social. 65: 572-594. Artículo en línea accesible en http://www.revistalatinacs.org/10/art3/ 920_Complutense/42_Pinuel.html, 2010.

Sánchez, G. Guerra y política en la sociedad colombiana. Bogotá: Punto de Lectura, 2008.

Sani, I. et al. «Political cartoons as a vehicle of setting social agenda: The newspaper example». Asian Social Science. Vol. 8(6):156-164. Artículo en línea accesible en www.ccsenet.org/ass, 2012.

Van Dijk, T. Ideología. Barcelona: Gedisa, 1999.

Villoro, L. El concepto de ideología. $2^{\mathrm{a}}$ ed. México, D.F.: Fondo de Cultura Económica, 2007.

Fuentes de las imágenes

Imagen 1: Mariano Ospina, chulavita. http://uwww.flickr. com/ photos/8069053@N08/2495928059/ (acceso: 12 jun 2012).

Imagen 2: «Desplantes de arrabal». En: Acevedo, D. (2009). Política y caudillos colombianos en la caricatura editorial, 1920-1950: estudio de los imaginarios políticos partidistas. Medellín: La Carreta Editores-Universidad Nacional de Colombia, pág. 145.

Imagen 3: «El regreso». En: Acevedo, D. (2009). Política y caudillos colombianos en la caricatura editorial, 1920-1950: estudio de los imaginarios políticos partidistas. Medellín: La Carreta Editores-Universidad Nacional de Colombia, pág. 178.

Imagen 4: Osuna, H. «Futurible», El Espectador, domingo 19 de agosto de 2012, pág. 45.

Imagen 5: «Infle y desinfle», González, B. (2009). La caricatura en Colombia a partir de la independencia. Bogotá: Biblioteca Luis Ángel Arango, pág. 134.

Imagen 6: «Tácticas conservadoras», En: Acevedo, D. (2009). Política y caudillos colombianos en la caricatura editorial, 1920-1950: estudio de los imaginarios políticos partidistas. Medellín: La Carreta Editores-Universidad Nacional de Colombia, pág. 17. 